\section{TUBERCULOSIS IN PAKISTANIS IN BRADFORD}

\author{
BY
}

\section{K. STEVENSON, M.B., M.R.C.P.Ed. Consultant Chest Physician, Bradford}

In 1954 it became noticeable that Asians had started to settle and form a colony in the central wards of the City of Bradford. Since 1954 this colony has steadily increased in size-so much so that their presence is obvious to any visitor to the city.

It was during 1954 that Asians with tuberculosis were first seen at the Bradford Chest Clinic. The clinical impression at the time was that pulmonary tuberculosis in Asians was acute in type and of recent onset. Since 1954 the number of Asian patients attending the Chest Clinic has increased at an alarming rate and a high incidence of tuberculosis has been discovered. In 1961 one out of every three new male patients seen at the Chest Clinic was an Asian, and the number of cases of tuberculosis discovered in male Asians was numerically greater than in all other adult males resident in the city.

Since 1955 the problem of tuberculosis in Asians has been under constant scrutiny, and determined efforts have been made to keep the resident Asian population under the closest possible radiological supervision. Investigations have been undertaken to determine the date of diagnosis in relation to the time of immigration, to decide whether the Asians had a tuberculous infection at the time of immigration or whether they developed disease in this country, and to determine if $x$-ray examination of the chest on arrival in Britain would have been a profitable measure in the control of tuberculosis in the Asian population resident here.

The aims of this paper are twofold: firstly, to state the size of the problem; and, secondly, to relate the date of diagnosis to the time of immigration.

Approximately $80-85 \%$ of the Asians in Bradford are Pakistanis ; as this investigation primarily concerns Pakistanis, reference is made not to Asians but to Pakistanis.

The Pakistanis living in Bradford come from the rural and underdeveloped areas of Pakistan. Before immigration most of them worked on the land; very few speak English and only a minority have had previous experience of industry. There are only a few Pakistani women and children. Unlike the West Indians, the immigrant Pakistanis are all males between the ages of 20 and 40 ; most intend to stay in Britain four or five years. During their time in Britain the Pakistanis support their families by sending money home to Pakistan; they also hope to save enough money to buy more land on their return home. Only a small number intend to settle and make their home in this country.

The Pakistanis come to the Midlands and Bradford on account of the availability of employment. To pay their air fares to Britain they borrow money from their friends and relatives, frequently those already resident here.

In Bradford most of the Pakistanis work in the combing industry of the wool textile trade, where the atmosphere tends to be hot and humid. Indeed, many mills are staffed entirely by Pakistanis during the night shift.
They are also employed in the engineering industry and a few on public transport. They live in the older, central wards of the city, and although the Health Department does its best to prevent overcrowding this remains a problem.

Many attempts have been made to estimate the number of Pakistanis in the city: the health authorities, after consultation with industries employing Pakistani labour, with the Ministry of Labour, with the National Assistance Board, and from surveys of households occupied by Pakistanis, estimated that the resident Pakistani population in Bradford at the beginning of 1961 was somewhere between 5,500 and 6,000. The population of Bradford C.B. remained static and unchanged at 289,000 from the time of the Census in 1951 up to 1960. At the Census in 1961 the population had increased by 6,000 to 295,000 . It seems reasonable to suppose, as there has been no evidence of any other movement of population, that the Health Department's estimate of Pakistanis in January, 1961, was correct and that the increase in population by 6,000 was the result of Pakistani immigration.

Since 1959 employment in Bradford has been difficult to obtain and it has become the accepted practice for all new arrivals from Pakistan to register at the Ministry of Labour. The numbers of new arrivals from Pakistan registering at the Ministry of Labour for the first time were 330 in 1959,216 in 1960 , and 2,802 in 1961 (Table I). These figures do not include Pakistanis moving into Bradford from other areas. Each month approximately 60 Pakistanis move in and out of the city, to and from other centres. In 1961, according to the Ministry of Labour, there were almost 3,000 new arrivals in Bradford from Pakistan at a rate of approxi-

TABLE I.-New Arrivals from Pakistan Registering at Ministry of Labour for First Time During 1961

\begin{tabular}{c|c|c|c|c|c|c|c|c|c|c|c|c}
\hline & $\begin{array}{c}\text { Jan } \\
\text { No. }\end{array}$ & Feb & Mar. & Apr. & May & June & July & Aug. & Sep. & Oct. & Nov. & Dec. \\
\hline
\end{tabular}

mately 60 a week. From the available evidence it would appear that the Pakistani population in Bradford at the beginning of 1961 was 6,000 and that at the end of the year it had increased to 9,000 . In December, 1961, the executive council reported that 9,000 Pakistanis had registered with practitioners, which confirms that the estimated number of Pakistanis resident in Bradford was reasonably correct.

\section{Notifications of New Cases of Tuberculosis in Bradford, 1951-61}

Table II shows the trend of notifications of tuberculosis at the Bradford Chest Clinic during the past 10 years. As this paper is primarily concerned with Pakistanis no attempt has been made to consider other

TABLE II.-Bradford Chest Clinic. Number of Cases Notified Suffering from Tuberculosis, 1951-61

\begin{tabular}{|c|c|c|c|c|c|c|c|}
\hline & \multicolumn{3}{|c|}{ Non-Pakistani } & \multicolumn{3}{|c|}{ Pakistani } & \multirow{2}{*}{ Total } \\
\hline & Men & Women & Children & Men & Women & Children & \\
\hline $\begin{array}{l}1951 \\
1952 \\
1953 \\
1954 \\
1955 \\
1956 \\
1957 \\
1958 \\
1959 \\
1960 \\
1961\end{array}$ & $\begin{array}{l}107 \\
111 \\
167 \\
174 \\
177 \\
150 \\
159 \\
147 \\
120 \\
118 \\
110\end{array}$ & $\begin{array}{r}69 \\
55 \\
115 \\
113 \\
101 \\
120 \\
110 \\
92 \\
59 \\
66 \\
56\end{array}$ & $\begin{array}{l}15 \\
11 \\
32 \\
40 \\
31 \\
31 \\
31 \\
20 \\
16 \\
17 \\
20\end{array}$ & $\begin{array}{r}2 \\
1 \\
4 \\
12 \\
20 \\
21 \\
26 \\
67 \\
83 \\
61 \\
124\end{array}$ & $\begin{array}{l}= \\
= \\
\bar{Z} \\
\overline{3} \\
4 \\
2 \\
3 \\
2\end{array}$ & $\begin{array}{l}\frac{2}{1} \\
\frac{1}{7} \\
\frac{1}{5} \\
\frac{5}{1} \\
1\end{array}$ & $\begin{array}{l}195 \\
178 \\
319 \\
340 \\
329 \\
322 \\
330 \\
330 \\
285 \\
\mathbf{2 6 7} \\
343\end{array}$ \\
\hline
\end{tabular}


groups, although it is worth recording that there is very little immigration from Ireland or from the West Indies into Bradford.

In 1952 there was a change in personnel and in accommodation at the Bradford Chest Clinic. This accounts for the increase in the number of notifications between 1951 and 1953 ; this rise is not statistically significant. The policy with regard to notifications has remained unchanged during the past 10 years. Since 1954-5 there has been a steady decline in the number of notifications in the British population despite intensified search for cases; this decline is in keeping with the experience of other centres. The annual rate of occurrence since 1955 has dropped by $50 \%$ in women and by $33 \%$ in men. With regard to the children, the numbers are too small to be statistically significant. Nevertheless, there has been a gradual decrease in the boys and girls under the age of 15 found to have a primary tuberculous infection. In Bradford the decline in incidence of tuberculosis has been offset by a marked increase in the numbers of new cases discovered in Pakistanis. During 1961 there were 127 new cases of tuberculosis diagnosed in Pakistanis compared with 186 in all other persons. On comparing the incidence of tuberculosis in the adult male population there were 124 new cases in Pakistanis and 110 cases in all other males. It is evident, therefore, that the tuberculosis rate in the male Pakistani population now exceeds that in all other males resident in Bradford.

The annual rate of occurrence of tuberculosis in the British population in Bradford in 1958-61, accepting the population as 290,000 , is as follows: 1958, 259 cases, $0.09 \%$ per annum ; 1959,195 cases, $0.07 \%$ per annum; 1960,201 cases, $0.07 \%$ per annum; 1961, 186 cases, $0.06 \%$ per annum.

In trying to find the annual rate in the Pakistani population it is very difficult to determine with any accuracy the number resident in the city at any given time, as the population is constantly increasing and statistics are bound to be inaccurate. Estimates of the Pakistani population, as has been shown, can be made only by indirect means. From the Health Department's statistics and from the Census in 1961 it is accepted, nevertheless, that the population of Pakistanis at the beginning of 1961 was 6,000 and that during the year it increased by 3,000 to 9,000 . The figures from the Ministry of Labour confirm that the rate of immigration was not uniform throughout the year; by June the number had increased to 7,000 and by December to 9,000 . Almost $50 \%$ of the immigrants $(1,419)$ arrived in the city during September to December. In accepting a figure on which to base the rate of incidence of tuberculosis in Pakistanis for the year 1961, the number estimated to have been in the city in June $(7,000)$ has been accepted as giving the fairest estimate of the mean population. During 1961 there were 127 new cases of tuberculosis notified in Pakistanis; these notifications, however, were evenly distributed throughout the whole year.

Accepting 7,000 as the mean population, the rate of incidence of tuberculosis among the Pakistanis during 1961 was $1.8 \%$. In 1959 when the estimate of Pakistanis in the city was 5,000 there were 90 new cases of tuberculosis among them, which also gives a rate of $1.8 \%$ for 1959. Although these figures cannot be substantiated it is thought that on the whole they are conservative estimates and that $1.8-2 \%$ is a fair assessment of the present annual incidence of tuberculosis in the Pakistani population. This rate is 30 times greater than that in the British population. In other words, 10,000 Pakistanis will produce as many cases of tuberculosis as 300,000 British persons. If the tuberculosis rate in Pakistanis is $18-20$ per 1,000 , we can anticipate a further 180 new cases in Bradford in the current year. During the first three months of 196271 new cases of tuberculosis have been discovered in Pakistanis at the Chest Clinic, which suggests that the incidence of tuberculosis is higher than the estimated 20 per 1,000 , and that this estimate is probably a minimal rate. These numbers also give some indication of the size of the problem and also of the strain on clinic services.

\section{Clinic Attendances 1961}

An analysis of the attendances during 1961 gives a reasonable indication of the number of Pakistanis referred to the Bradford Chest Clinic. There were 13,087 total attendances, of which 5,160 were for the first time (Table III). There were 4,070 new patients referred by practitioners for consultation or for $x$-ray examination and 1,090 for examination as contacts. The total number of new Pakistani patients was 956-almost one in five of every patient seen at the clinic.

\begin{tabular}{|c|c|c|c|c|c|}
\hline & & Men & Women & Children & Total \\
\hline \multicolumn{6}{|c|}{ All New Patients, 1961} \\
\hline \multirow{3}{*}{$\begin{array}{l}\text { New referrals } \\
\text { New contacts }\end{array}$} & $\cdots 1$ & 2,305 & 1,508 & 257 & 4.070 \\
\hline & $\cdots$ & & & & \\
\hline & & 2,830 & 1,675 & 655 & 5,160 \\
\hline \multicolumn{6}{|c|}{ New Pakistanis Seen in 1961} \\
\hline \multirow{3}{*}{$\begin{array}{l}\text { New referrals } \\
\text { New contacts }\end{array}$} & $\cdots$ & 502 & 17 & 5 & 524 \\
\hline & $\cdots$ & 410 & & & \\
\hline & & 912 & 25 & 19 & 956 \\
\hline
\end{tabular}

Immigration of Pakistanis is almost exclusively an immigration of males, and Table III shows that out of a total of 2,830 male patients seen for the first time 912 were Pakistanis, which is one in three of all new male patients seen.

An analysis of all notifications in 1961 (313) is given in Table IV to show the source of referral and to indicate the number diagnosed after contact examinations. It is interesting to note that $40 \%$ of all cases were referred direct by their own practitioners, that $30 \%$

\begin{tabular}{|c|c|c|c|c|c|c|c|}
\hline \multirow{2}{*}{ Source } & \multicolumn{3}{|c|}{ Non-Pakistani } & \multicolumn{3}{|c|}{ Pakistani } & \multirow{2}{*}{ Total } \\
\hline & Men & Women & Children & Men & Women & Children & \\
\hline $\begin{array}{l}\text { G.P. } \\
\text { reterrals } \\
\text { M.M.R. } \\
\text { Hospital } \\
\text { Contacts } \\
\text { Others .. }\end{array}$ & $\begin{array}{r}42 \\
19 \\
33 \\
2 \\
14\end{array}$ & $\begin{array}{r}17 \\
8 \\
20 \\
1 \\
10\end{array}$ & $\begin{array}{r}3 \\
5 \\
9 \\
3 \\
\end{array}$ & $\begin{array}{r}57 \\
9 \\
36 \\
16 \\
6\end{array}$ & $\frac{1}{1}$ & $\frac{-}{1}$ & $\begin{array}{r}120 \\
36 \\
95 \\
29 \\
33 \\
\end{array}$ \\
\hline Total & 110 & 56 & 20 & 124 & 2 & 1 & 313 \\
\hline
\end{tabular}

were diagnosed after admission to a general hospital for investigation, that $10 \%$ were discovered by M.M.R. examination, and a further $10 \%$ through contact examinations.

With regard to contact-tracing, 3.5 persons were examined to every index case notified, and the rate of pick-up in the British population, which included nine children, was $1.8 \%$, whereas in the Pakistani group, 
which was almost exclusively adult males, it was $4 \%$. Contact-tracing since 1955 has been extended from domestic and family contacts to include all works contacts. In the case of the Pakistanis this has been a thankless task, and an average of four to five visits have been made to each household to obtain co-operation and consent to $x$-ray examination. As an average of 80 Pakistanis attend for contact examinations each week, help has been sought for these examinations to be undertaken by the local-based M.M.R. unit.

\section{Study of Pakistanis with Tuberculosis, 1955-9}

When it was noted in 1955 that Pakistanis with acute and florid tuberculosis were attending at the chest clinic, it was decided that all Pakistanis with active tuberculosis should be admitted to one hospital for investigation, treatment, and study. Initial domiciliary treatment was not undertaken, although domiciliary chemotherapy was continued after hospital discharge.

Between January, 1955, and October, 1959, 150 Pakistanis with tuberculosis were admitted to Middleton Hospital from the Bradford Chest Clinic area. In the survey there were 141 men, 5 women, and 4 children; 131 had pulmonary and 19 non-pulmonary disease.

The men were admitted to one ward, where it was possible to observe dietetic and religious customs. At no period during the time of investigation was there a shortage of interpreters. Information in all cases with regard to the country of origin, the time of immigration, and the length of stay in the United Kingdom, together with a full medical history and details of previous treatment and $x$-ray examinations, were recorded and analysed.

In this study an attempt was made to discover whether the Pakistanis had active tuberculosis at the time of immigration or whether they developed the disease in this country, also to determine if $x$-ray examination of the chest would have been a practical measure in the control of tuberculosis in the Pakistani immigrant.

Each case was carefully assessed after full clinical, radiological, and bacteriological examination. The response to treatment, the time of sputum conversion, and the gain in weight, together with the study of serial $x$-ray films, were studied.

In 95 patients with pulmonary disease it was thought that it was of fairly recent onset, and that 36 had had an obvious relapse of previous disease.

Although any classification of pulmonary disease is unreliable it has been decided that for the purpose of this survey those patients discovered to have had a previous tuberculous infection, with radiological evidence, should be included in the group thought to have had a relapse. All other cases have, rightly or wrongly, been included in the group in which the disease was thought to have been of recent onset. This group includes those discovered on mass radiography to have a primary lesion with enlarged mediastinal glands and also all patients in whom the radiological appearance was of acute post-primary tuberculosis. Many had extensive exudative lesions and also areas of bronchopneumonia. Cavitation was a common finding.

Patients Thought to Have Disease of Recent Onset (95).-The majority in this group were acutely ill ; they had a high fever, the illness was of short duration, and many were working full-time in industry a fortnight before admission to hospital. Over $30 \%$ in this group were initially admitted to a general medical ward for investigation of a P.U.O. Sputum was positive in 45 (47\%). Pleural effusions were present in $13(14 \%)$ and $40(44 \%)$ had associated non-pulmonary lesions. The non-pulmonary lesions were predominantly enlarged and palpable cervical glands. Confirmation of the diagnosis by biopsy was undertaken in a small number. There were two cases of miliary tuberculosis and one with a progressive primary lesion and tuberculous pericarditis.

Patients Thought to Have Had a Relapse of Previous Disease (36). - In these patients there was obvious radiological evidence of previous post-primary tuberculosis: many had fibrotic and cavitated lesions, all had areas of fibrosis and evidence of previous lung damage. Ten admitted to treatment in Pakistan; one had been too ill to work in Pakistan and had come to Britain. Another, the wife of a Pakistani already resident in Bradford, was discovered to have extensive bilateral fibro-cavernous disease within a week of arrival. Her sputum was positive and resistant to the three standard antituberculous drugs. This was the only bacillus in the whole series that was resistant; in all other cases sputum sensitivity tests confirmed that the organisms were fully sensitive to streptomycin, P.A.S., and isoniazid. There were no pleural effusions in this group; 17 (47\%) had positive sputum and 7 (19\%) non-pulmonary lesions.

Nearly half the patients with pulmonary tuberculosis were discovered to be infectious and were excreting tubercle bacilli in the sputum.

Non-pulmonary Cases (19).--In this group three had enlarged non-caseating cervical glands, eight had cervical adenitis with an abscess, one had tuberculosis of the dorsal spine, three had osteomyelitis or rib with a cold abscess, two had peritonitis, and two had renal disease. Tubercle bacilli or a positive gland biopsy was obtained in $16(84 \%)$. Two patients in this group admitted to previous treatment in Pakistan; one had a long-standing discharging sinus from glands in the neck. $X$-ray examination of these patients excluded evidence of active pulmonary disease. Five had obvious calcified and healed primary lesions and two had pleural thickening which was possibly the result of a previous pleural effusion.

\section{Treatment}

The response to treatment was very satisfactory in all patients, and in many cases it was dramatic. The three standard drugs were prescribed and cortisone was used in 15 to cover drug desensitization. The average gain in weight was $17 \mathrm{lb}$. (7.7 kg.) and the average duration in hospital six months. There were two deaths-one from cerebral haemorrhage and one from uraemia in a case of hypertension. No death occurred from tuberculosis.

A follow-up showed that there were eight readmissions-five with orthopaedic lesions, one with relapse of pulmonary tuberculosis, one with a drug reaction, and one with bronchitis.

The date of diagnosis in relation to the time of immigration to the United Kingdom is recorded in Table V. The three groups have been recorded separately.

\section{Time of Diagnosis in Relation to Time of Immigration}

Table V shows that $49(33 \%)$ cases were diagnosed within 12 months of immigration and $101(67 \%)$ after at least one year's residence in Britain. In the group 
TABLE V-Time of Diagnosis in Relation to Time of Immigration to U.K.

Diagnosed Within 12 Mouths

\begin{tabular}{l|r|r|r|r|r}
\hline & \multicolumn{4}{|c|}{ Months } & Total \\
\cline { 2 - 5 } & $0-3$ & $3-6$ & $6-9$ & $9-12$ & \\
\hline Cases of recent onset (95) & 3 & 9 & 4 & 12 & 28 \\
Nön-pulmonsed disease (36) & 4 & 3 & 2 & 4 & 13 \\
\hline & 1 & 1 & 4 & 2 & 8 \\
\hline
\end{tabular}

Diagnosed After 12 Months

\begin{tabular}{l|r|r|r|r|r|r}
\hline & \multicolumn{5}{|c|}{ Years } & Total \\
\cline { 2 - 6 } & $1-2$ & $2-3$ & $3-4$ & $4-5$ & $5-10$ & \\
\hline Cases of recent onset (95) $\ldots$ & 20 & 20 & 8 & 12 & 7 & 67 \\
Non-pülmonary casease (36) & 5 & 4 & 4 & 2 & 8 & 23 \\
\hline & 30 & 28 & 12 & 14 & 17 & 101 \\
\hline
\end{tabular}

with pulmonary disease of recent onset $28(30 \%)$ were diagnosed within 12 months, and in the group where there had been previous disease $13(36 \%)$ relapsed within the first year. In this survey, therefore, over one-third of all Pakistanis with pulmonary tuberculosis were diagnosed within 12 months of immigration. In the group of 95 patients whose disease was thought to have been of recent onset $30 \%$ were diagnosed within a year of immigration, $20 \%$ in the second year after immigration, $20 \%$ in the third year, and $30 \%$ after three years' residence. It is evident, therefore, that out of 131 patients diagnosed with pulmonary disease, $67(50 \%)$ developed a " recent " infection after at least 12 months' residence in Britain.

In assessing the value of $x$-ray examination of the chest at the time of immigration there can be no doubt that all 36 patients who had a relapse of disease, together with most of the 28 discovered to have an active postprimary infection within the first 12 months of residence, would have been recalled for investigation after $x$-ray examination. It seems likely, therefore, that about $40 \%$ of the total number of cases in this series would have been picked up for investigation; if we consider only those patients who later developed a pulmonary infection then the pick-up rate would have been about $50 \%$.

\section{Discussion}

From the available statistics of the Pakistani population in Bradford it is estimated that the annual rate of incidence of tuberculosis among them is at least 20 per 1,000 , which is 30 times greater than the incidence in the British population in this city; there is also a high incidence of tuberculosis in the Pakistani contacts, with a rate of 40 per 1,000 . From the in-patient survey it is evident that $33 \%$ of the cases studied were diagnosed within 12 months of immigration, that at least $50 \%$ of those eventually developing a pulmonary infection probably acquired it in this country, and that between 40 and $50 \%$ had an abnormal $x$-ray picture at the time of immigration.

Springett (1958), in a survey of tuberculosis in immigrants, confirmed that there was a high incidence of tuberculosis in the resident Asian population in Birmingham, also that the disease was predominantly chronic in type and present at the time of immigration. Roe (1959), on the other hand, from a study on 35 Asians with tuberculosis concluded that in the majority the disease was recent in onset and probably acquired in this country. Roe also reported a high incidence of negative Mantoux reactors in Asian contacts. Corbett (1961) recorded a small series of 10 cases of tuberculosis in Indians from Bombay and observed that one-third of the male and two-thirds of the female contacts were Mantoux-negative.

Unfortunately, owing to the numbers involved and also on account of the difficulty and the time spent in getting Pakistanis to attend for contact $x$-ray examinations at the Chest Clinic, it has not been possible to include a Mantoux survey.

If there are Mantoux-negative Pakistanis in the community, as suggested by Roe and by Corbett, it seems reasonable to suppose that Pakistanis with active tuberculosis at the time of immigration are spreading infection in the overcrowded Pakistani households. This certainly seems to be the case in Bradford, where the annual incidence of tuberculosis in Pakistani contacts is 40 per 1,000 .

It would appear, therefore, that both Springett and Roe are right and that the problem is twofold-the tuberculous immigrant and the susceptible Pakistani.

The Tuberculosis and Diseases of the Chest Group of the British Medical Association reported that mass radiography surveys of the Asian population gave a yield of 25 per 1,000 against the figure of 1 per 1,000 for the British population (Brit. med. J., 1961). Since 1958 in Bradford we have held annual surveys for the Pakistanis and have used every possible method to get them to the $x$-ray machine-by advertising at Pakistani film shows, and by household canvassing, lectures, and repeated street surveys with the mobile $x$-ray van in the Pakistani districts, all without much success. The attendances and the pick-up rate have been low and disappointing. Even in surveys at factories employing Pakistani labour it is difficult to obtain their co-operation and willingness to have an $x$-ray examination. It is considered, nevertheless, that $x$-ray examination of the Pakistanis while at work gives the best chance of success in maintaining radiological supervision.

There are no records of recent surveys of tuberculous morbidity in Pakistan; in Bombay Shah et al. (1960) reported that the tuberculous morbidity following mass radiography surveys depends on social class and varies from 0.1 to $10 \%$.

The rate of tuberculosis in India and Pakistan is high, and this is well recognized. With regard to immigration of Asians into the United Kingdom, those in authority should be aware of the problem and take reasonable precautions to safeguard against imported tuberculosis and to prevent its spread. Present methods of treatment and prevention of tuberculosis in this country are directed and are moving successfully towards the eradication of tuberculosis; it would be a great misfortune if the anti-tuberculosis programmes were to fail because uncontrolled importation of tuberculosis was allowed to continue.

The Tuberculosis and Diseases of the Chest Group of the British Medical Association recommended on November 8, 1961, that no immigration should be permitted without complusory $x$-ray examination of the chest and that persons discovered to be suffering from tuberculosis must be subject to compulsory treatment or rejected. They also reported that in the first eight months of 1961 26,700 immigrants arrived from India and Pakistan and that if immigration on this scale continued there would be 40,000 immigrants from Asia 
each year. If immigration continues at the present rate 800-1,000 new cases of tuberculosis in immigrants from Asia can be expected annually.

The experience in Bradford endorses the recommendations of the Tuberculosis and Diseases of the Chest Group Committee. Furthermore, the committee advocates that all immigrants, whether from the Commonwealth or not, should have an $x$-ray examination of the chest at the point of arrival in the United Kingdom. The success of the anti-tuberculosis programmes towards the eradication of tuberculosis is not an achievement which should be regarded lightly and is one that we should endeavour to maintain.

\section{Summary}

Tuberculosis in Pakistanis is 30 times more common than in the British population.

Of the Pakistanis with tuberculosis, $33 \%$ are diagnosed within 12 months of immigration and between 40 and
$50 \%$ have abnormal $x$-ray pictor at the time of immigration.

Of the Pakistanis with tubercukosis, 50\% develop the disease in this country.

The recommendation of the Tuberalosis and Diseases of the Chest Group of the British Medical Association is strongly endorsed-namely, that all immigrants should have an $x$-ray examination of the chest at the port of entry into the United Kingdom.

I thank Dr. D. M. Prinsley, who was deputy superintendent of Middleton Hospital at the time of the investigation, and who reviewed all the cases and made many helpful suggestions, and Dr. John Douglas, M.O.H. Bradford, who gave every available assistance.

\section{REFERENCES}

Brit. med. J., Suppl., 1961, 2, 254.

Corbett, J. T. (1961). J. Coll. gen. Practit., 4, 332.

Roe, J. T. Nicol. (1959). Tubercle (Lond.), 40, 387.

Shah, J. R., Warawdekar, M. S., Mehta, R. H., and Deshmukh, P. A. (1960). Indian J. med. Sci., 14, 948 .

Springett, V. H. (1958). Brit. J. prev. soc. Med., 12, 135.

\section{TUBERCULOSIS AMONG INDIAN IMMIGRANTS TO A MIDLAND INDUSTRIAL AREA}

\section{J. ASPIN, M.A., M.D., D.M.R.D.}

At the end of 1960 it was estimated that there were in the Wolverhampton neighbourhood some 3,000 adult Indian immigrants and a very much smaller number of Pakistanis, altogether amounting to about $2 \%$ of the local adult population. Before 1954 there were few Asiatic immigrants. In 1954 and in each subsequent year up to 1959 larger, though unascertained, numbers arrived each year, some to stay, others to move to other areas. Restrictions imposed by the Government of India temporarily slowed down the rate of emigration, but since 1960 Indians have again been arriving in rapidly increasing numbers. These later immigrants include a higher proportion of wives and families.

\section{Incidence}

Between 1950 and 1954 there was only one known Indian case of pulmonary tuberculosis in the area. Since January, 1954, 62 adult Indians and five adult Pakistanis have been found to be tuberculous, 60 with pulmonary and seven with non-pulmonary disease. It is interesting to note that of the 62 Indians, $41(66 \%)$ came from the Jullundur districts of East Punjab and $10(16 \%)$ from Surat districts near Bombay, a distribution which is as unlikely to have arisen by chance as the reported predominance of Gujeratis in another Midland area only a few miles away, and the extremely high proportion of Pakistanis among the Asiatic immigrants in Bradford (D. K. Stevenson, 1959, personal communication).

Although it is realized that this type of selective immigration to localized areas may lead to local differences in the prevalence of tuberculosis among Asiatics, for the sake of brevity in all that follows Indians and/or Pakistanis are referred to as Indians.

Table I shows the number of pulmonary tuberculosis cases diagnosed year by year. There are two striking points. Firstly, the annual local recognition of new cases among Indians is rising progressively. Secondly, among Indians arriving in 1954 and 1955 there has been a steady subsequent recognition of disease year by year up to 1961 .

TABLE I.-Year of Arrival and Year of Diagnosis Among 60 Indian Cases of Pulmonary Tuberculosis in the Wolverhampton Neighbourhood

\begin{tabular}{|c|c|c|c|c|c|c|c|c|}
\hline \multirow{2}{*}{ Year of Arrival } & \multicolumn{8}{|c|}{ Year of Diagnosis } \\
\hline & 1954 & 1955 & 1956 & 1957 & 1958 & 1959 & 1960 & 1961 \\
\hline Pre-1954 & 2 & 0 & 0 & 2 & 0 & 2 & 0 & 0 \\
\hline $\begin{array}{l}1954 \\
1955\end{array}$ & $\underline{-}$ & $\frac{1}{2}$ & $\begin{array}{l}1 \\
0\end{array}$ & 1 & $\frac{2}{3}$ & 2 & $\frac{2}{2}$ & $\frac{2}{3}$ \\
\hline & - & - & 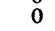 & 0 & 1 & 0 & 2 & 1 \\
\hline & - & - & - & 0 & 1 & 0 & 3 & 2 \\
\hline 19 & - & - & - & - & 0 & 2 & 1 & 2 \\
\hline & - & - & - & - & - & 0 & 1 & 2 \\
\hline & 一 & 一 & - & - & - & - & 2 & 4 \\
\hline Not known & 二 & 三 & $\bar{z}$ & 二 & 二 & $\overline{1}$ & 二 & $\underline{4}$ \\
\hline All years & 2 & 3 & 1 & 4 & 7 & 10 & 13 & 20 \\
\hline
\end{tabular}

Table II shows the rising proportion of Indians among locally diagnosed adult cases of pulmonary tuberculosis. Through lack of knowledge of the yearly number of Indians present in the area it is not possible to make wholly satisfactory comparisons. Assuming that during

TABLE II.-New Adult Cases of Pulmonary Tuberculosis in the Wolverhampton Neighbourhood, Showing the Proportion of Indians

\begin{tabular}{|c|c|c|c|c|c|c|c|c|}
\hline Year of Diagnosis & 1954 & 1955 & 1956 & 1957 & 1958 & 1959 & 1960 & 1961 \\
\hline & 238 & 222 & 241 & 216 & 194 & 162 & 159 & 181 \\
\hline $\begin{array}{l}\text { No. of } \\
\text { cases } \\
\text { Percent }\end{array}$ & 2 & 3 & 1 & 4 & 7 & 10 & 13 & 20 \\
\hline $\begin{array}{l}\text { age of } \\
\text { totals }\end{array}$ & 0.8 & 1.4 & 0.4 & 1.9 & 3.6 & 6.2 & 8.2 & 11.0 \\
\hline
\end{tabular}

1960 there were 3,000 adult Indians and 150,000 other adults living in the area, and disregarding age differences, it appears that in 1960 over four times as many new cases of pulmonary tuberculosis were recognized among Indian immigrants as might have been expected among a similar number of local inhabitants. If it had been 